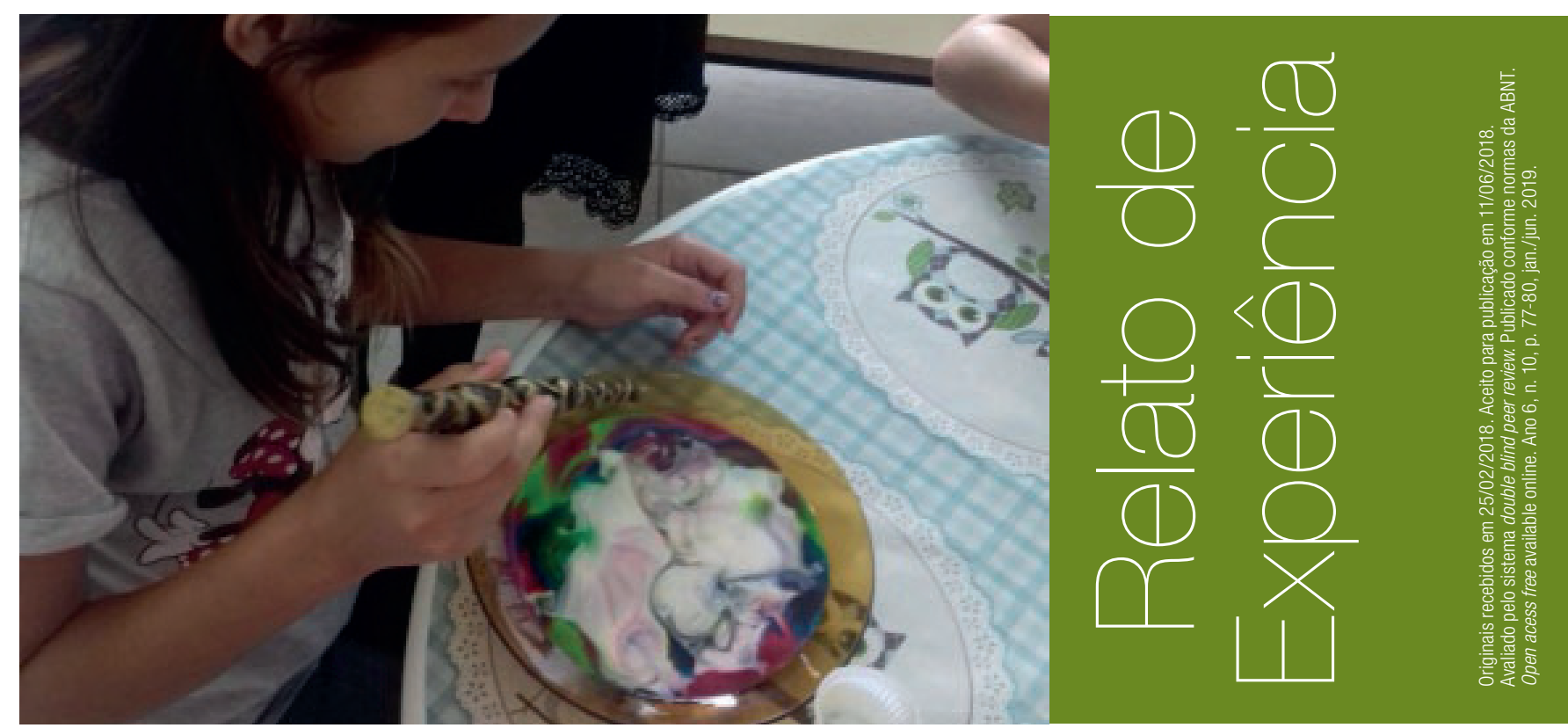

\title{
Alquimia, Magia e Química: relato de experiência de um projeto de extensão
}

\author{
Gizelle I. Almerindo - gizelle.almerindo@univali.br ${ }^{1}$ \\ Anelise Ehrhardt - anelisee@univali.br² \\ Patrícia F. S. Costódio - pscherer@univali.br ${ }^{3}$
}

\section{RESUMO}

Neste artigo é apresentado o relato de experiência do projeto de extensão denominado "Divulgação e popularização da Química no Centro de Educação em Tempo Integral Verde Vale" (Itajaí/SC). 0 objetivo da atividade foi o de explorar o encanto do Dia das Bruxas abordando-se a alquimia na história da Química na educação das séries iniciais com crianças de 9 a 12 anos. A experimentação mediante uso de leite, corante, detergente e uma "varinha mágica" despertou 0 interesse científico dos estudantes.

\section{PALAVRAS-CHAVE}

Projeto de extensão. Educação em Química. Alquimia. Bruxaria. Interesse Científico.

\footnotetext{
1 Doutora em Química pela Universidade Federal de Santa Catarina (UFSC), Professora da Escola do Mar, Ciência e Tecnologia da Universidade do Vale do Itajaí (UNIVALI).

2 Doutora em Engenharia de Materiais pela University of Fukui, Professora da Escola do Mar, Ciência e Tecnologia da Universidade do Vale do Itajaí (UNIVALI).

3 Mestre em Engenharia Ambiental pela Universidade Federal de Santa Catarina (UFSC), Professora da Escola do Mar, Ciência e Tecnologia da Universidade do Vale do Itajaí (UNIVALI).
} 


\title{
ABSTRACT
}

This article reports the experience of the Extension Project called "Divulgation and Popularization of Chemistry in the Fulltime Education Center Green Valley (Itajaí/SC)". The aim of the activity was to explore the charm of the Halloween Day approaching Alchemy in the History of Chemistry and applying it in the education of the early grades with children from 9 to 12 years. Experimentation using ingredients such as milk, dye, detergent, and a "magic wand" hand-made by the Volunteers aroused great enthusiasm, enabling the awakening of the scientific interest.

\section{KEYWORDS}

Extension Project. Chemistry Education. Alchemy. Witchcraft. Scientific Interest.

\section{Relato de experiência}

Avaliações nas quais estudantes brasileiros têm participado mostram resultados preocupantes quanto ao desempenho em ciências. Dentre as 72 nações avaliadas no ano de 2015, segundo a Organização para a Cooperação e Desenvolvimento Econômico (OCDE), o país ocupou a 63a posição em ciências (EDUCAÇÃO, 2016). Nesse contexto, uma contribuição para a mudança de tal cenário poderia ser feita mediante a divulgação e popularização da ciência mostrando a importância e 0 impacto dessa na sociedade (GIORDAN, 1999). Mais especificamente em relação ao ensino de Química para crianças, tem-se, conforme Cachapuz (2015, p. 125), a possibilidade de "ajudar os mais jovens a problematizar o senso comum e ter um olhar menos ingênuo sobre o mundo natural", assim como, "0 estudo das ciências/química é a melhor forma de conhecermos o mundo natural e deve começar desde cedo".

Cabe aos professores, pesquisadores e alunos um papel fundamental para a divulgação e popularização da Química. Ademais, de acordo com Ivanissevich $(2009$, p. 5):

\begin{abstract}
É também missão dos pesquisadores popularizar a ciência. É com a divulgação de seus trabalhos que os cientistas prestam contas à sociedade. Mostrando a produção do conhecimento feita no país, a comunidade científica se aproxima da população, que passa então a entender 0 verdadeiro valor de investir em pesquisa. Ao falar sobre seu trabalho, o cientista pode derrubar o muro da superespecialização, que torna os resultados de pesquisa de um especialista cada vez mais incompreensíveis para colegas de outras áreas. Além disso, bons artigos e programas de divulgação científica podem ser fontes complementares para professores do ensino fundamental, médio e universitário. Sem contar a possibilidade de se despertar vocações para carreiras científicas e tecnológicas. A socialização do saber produzido no país deve ser considerada, portanto, uma missão para o cientista. (IVANISSEVICH, 2009, p. 5).
\end{abstract}

Nessa perspectiva, o curso de Engenharia Química da Univali, através do projeto de extensão denominado de "Divulgação e Popularização da Química no Centro de Educação em Tempo Integral Verde Vale" (Cedin-VerdeVale), localizado em Itajai/SC, tem realizado atividades para crianças na faixa etária de 9 a 12 anos.

Tendo em vista a importância da história da Química na educação científica, fez-se uso do Dia das Bruxas para trabalhar a alquimia. Segundo Chassot (1995, p. 20), "A própria história da ciência não pode ser adequadamente observada sem se considerar, mesmo que panoramicamente, a história da filosofia, da educação, das religiões, das artes, das magias, [...]." Portanto, procurouse explorar 0 encanto do Dia das Bruxas, para fazer a relação entre a ciência e alquimia que envolve esse cenário. Os conhecimentos científicos envolvidos foram a solubilidade e a tensão superficial.

De forma dialogada e expositiva realizou-se um encontro de duas horas. No primeiro momento, em uma roda de conversa (Figura 1), procurou-se avaliar o conhecimento prévio dos alunos sobre 0 tema, sendo possível observar que os alunos desconheciam o significado da palavra alquimia. 
Para que eles se ambientassem com 0 tema, foram mostrados materiais que alquimistas utilizavam na antiguidade, tais como, o almofariz e o pistilo que são utilizados para moagem ou maceração de substâncias sólidas. Com muita atenção, os estudantes escutaram que os alquimistas foram responsáveis por uma série de descobertas cientificas e que, atualmente, para que se faça esse trabalho com segurança é necessário que estejam envolvidos profissionais de diversas formações como: químicos, engenheiros químicos, farmacêuticos, entre outros.

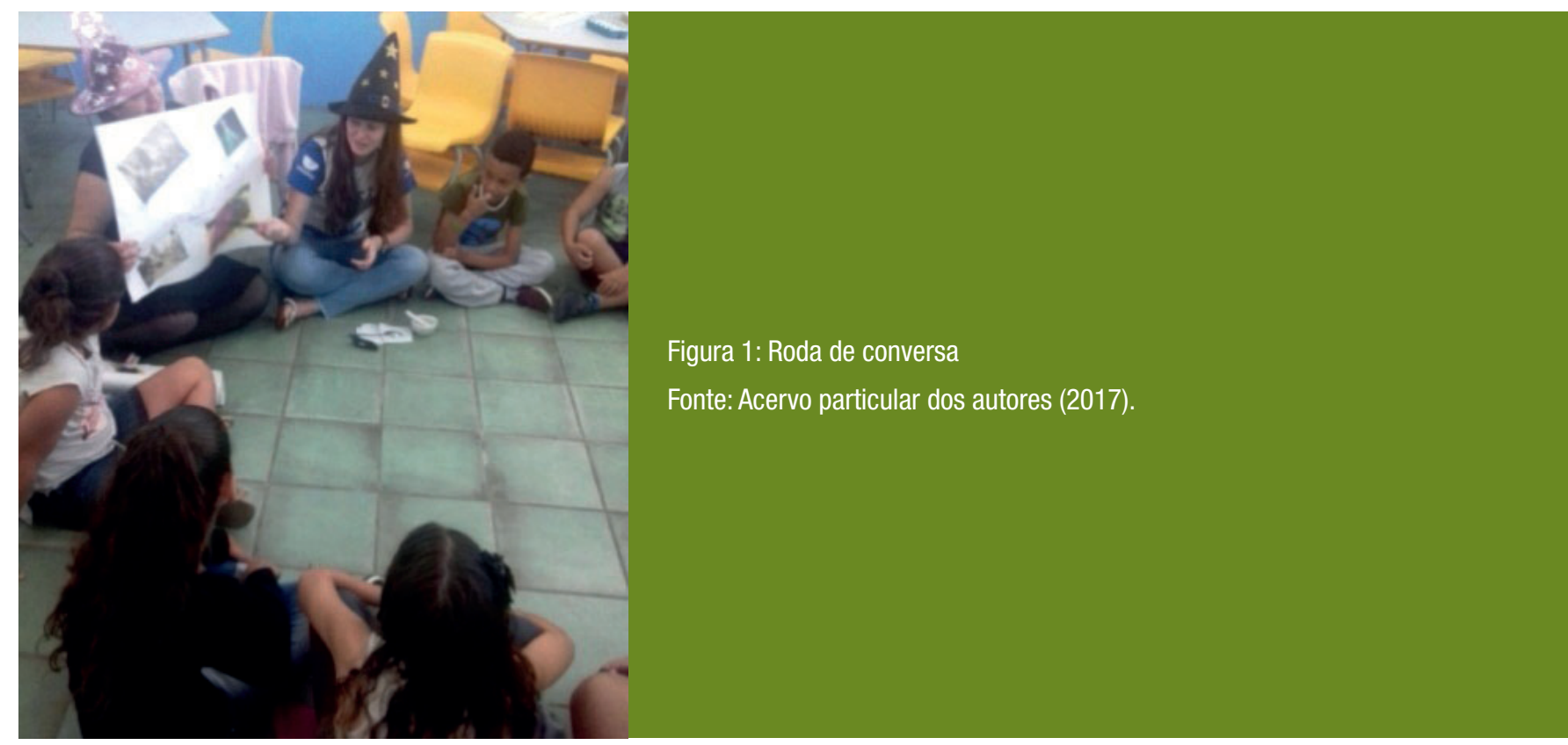

Numa referência ao castelo bruxo, sendo este conhecido como a escola de magia brasileira localizada na Floresta Amazônica do mundo de Harry Potter, mencionou-se com algumas adaptações, de forma figurativa, que no Brasil existia uma escola de magia e bruxaria (ROWLING, 2017). Tal como no castelo, as equipes foram divididas em três casas: laras (sábios e astutos), serpente de fogo (leais e destemidos) e uirapurus (honestos e dedicados). Na mesa referente à cada casa, foi colocado uma quantidade de leite e corante em pratos. Em separado, haviam copinhos com detergente. As professoras perguntaram aos alunos como iriam misturar o leite e corante se não havia colheres na mesa. Para que os alunos fizessem a mistura dos materiais, foram entregues "varinhas mágicas", que foram previamente confeccionadas (figura 2).

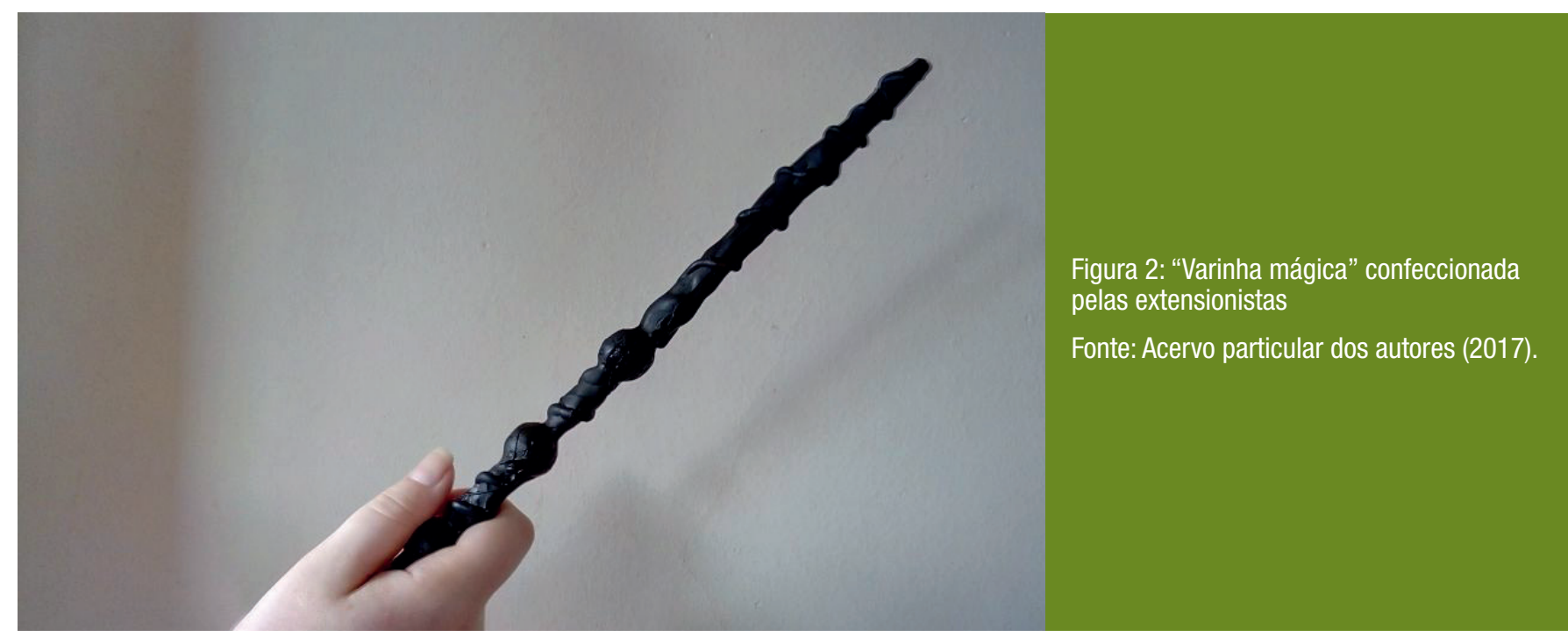

Por fim, foi explicado como deveriam proceder com o experimento, ou seja, colocar a ponta da varinha no detergente, em seguida colocá-la na mistura de leite com corante e observar. Depois desse processo, perguntou-se aos alunos se era mágica ou Química. As crianças ficaram 
eufóricas com as varinhas e com o experimento. Disseram: "é uma reação química" e "uma substância se mistura com a outra e muda de cor". Ainda, avaliaram a oficina como a "melhor atividade" perante todas as outras já realizadas pelo projeto de extensão. Em seguida, as crianças foram questionadas se a atividade estava relacionada à Química ou à magia sendo que a resposta foi "química com um pouquinho de magia". Ao final, explicou-se, de forma simples, que os corantes e o leite não se misturam devido à gordura presente nesse último, mas que 0 detergente é capaz de "quebrar" a força (tensão superficial) que impede que tais substâncias se misturem. Sendo assim, mencionou-se que há diferenças entre algumas substâncias que dificultam a mistura, porém, outra substância (um agente tensoativo) pode auxiliar em tal processo.

A oficina temática realizada vai ao encontro das palavras de Cachapuz (2015, p. 125), conforme: "são raros os estudos publicados dizendo respeito ao ensino da química para os mais pequenos (primeiros anos da escolaridade)". Portanto, o presente estudo baseou-se em um dos princípios da extensão, que é o de aproximar a comunidade acadêmica do público externo à universidade, e de contribuir com pesquisas na área de educação, já que "sabe-se pouco se e como é que tais assuntos são trabalhados pelos professores com os jovens alunos nos níveis iniciais, em particular sobre estratégias de ensino usadas e rigor científico adequado a esses níveis etários" (CACHAPUZ, 2015, p. 126).

Os seis acadêmicos envolvidos nas atividades, além de serem multiplicadores do conhecimento organizando e executando a oficina temática, puderam verificar que uma linguagem menos técnica pode auxiliar na construção do conhecimento para crianças (CACHAPUZ, 2015).

Atividades como essa também promovem a curricularização da extensão nas diferentes fases do curso e permitem que sejam trabalhados temas como experimentação de reações e processos com diferentes públicos. A ideia de criar práticas livres, com 0 objetivo de serem aplicadas ao projeto de extensão do curso, faz com que os alunos percebam que a ciência precisa ser pensada a partir de atividades do dia a dia.

\section{Referências}

CACHAPUZ, António F. Química nova na escola: um caso de sucesso. Química Nova na Escola, [s...], v. 37, p.121-126, 2015. Disponível em: http://qnesc.sbq.org.br/online/qnesc37_ especial_2/04-EA-107-15.pdf. Acesso em: 14 jun. 2018.

CHASSOT, Attico I. Alquimiando a Química. Química Nova na Escola, n.1 , p.20-22, maio 1995. Disponível em: http://qnesc.sbq.org.br/online/qnesc01/historia.pdf. Acesso em: 11 set. 2017.

EDUCAÇÃO, Carta. Brasil mantém últimas colocações no Pisa. Disponível em: www. cartaeducacao.com.br/reportagens/brasil-mantem-ultimas-colocacoes-no-pisa/. Acesso em: 15 fev. 2018.

GIORDAN, Marcelo. 0 papel da experimentação no ensino de Ciências. Química Nova na Escola, v. 10, n. 10, p.43-49, nov. 1999. Disponivel em: http://qnesc.sbq.org.br/online/ qnesc10/pesquisa.pdf. Acesso em: 31 jan. 2018.

IVANISSEVICH, Alicia. A missão de divulgar Ciência no Brasil. Ciência e Cultura, v. 61, n.1, p.4-5, fev. 2009. Disponível em: http://cienciaecultura.bvs.br/pdf/cic/v61n1/a02v61n1.pdf. Acesso em: 15 fev. 2017.

ROWLING, R K. Castelo bruxo. Disponível em: https://www.pottermore.com/writing-by-jkrowling/castelobruxo. Acesso em: 01 out. 2017. 


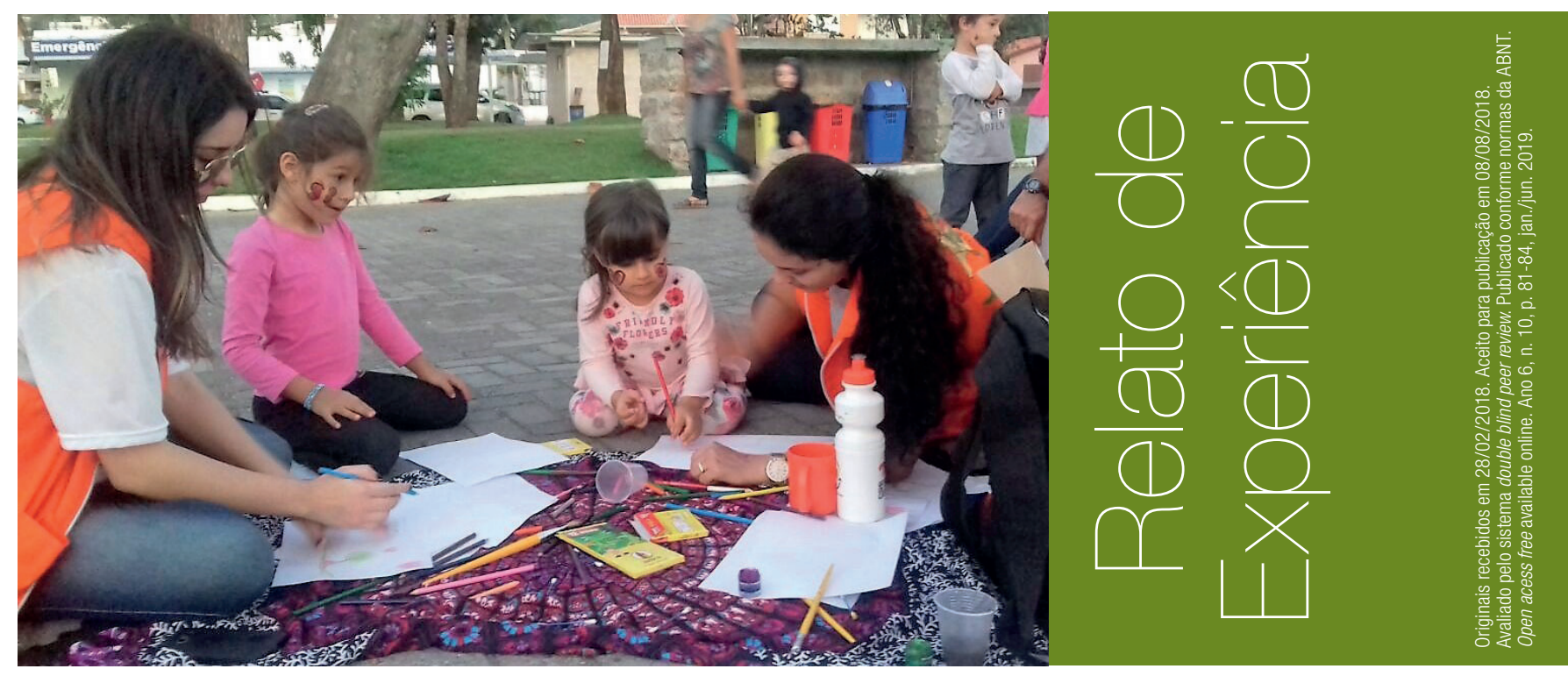

\title{
Extensão na prática: a interação institucional com a sociedade
}

\author{
Victória Luiza Schelbauer de Lima - victoriaschelbauer@gmail.com \\ Jerusa Fumagalli Schaf Nunes - jerusafumagalli@otmail.com²
}

\section{RESUMO}

0 presente relato de experiência visa apresentar as ações do Núcleo Extensionista Rondon (NER), que vem possibilitando 0 intercâmbio dos acadêmicos e a inserção da universidade em diferentes áreas de conhecimento, abrangendo nesta operação a Secretaria de Desenvolvimento Regional (SDR) de Braço do Norte, Criciúma, Laguna e Tubarão. 0 Instituto Federal de Santa Catarina (IFSC) é parceiro institucional nessa iniciativa, que busca o desenvolvimento regional, interdisciplinaridade e interação entre a universidade e a sociedade.

\section{PALAVRAS-CHAVE}

Núcleo Extensionista. Intercâmbio. Interdisciplinaridade. Interação.

\section{ABSTRACT}

The present experience report aims to present Rondon Extension Nucleus (NER - UDESC) actions, which has made possible the exchange of academics and the insertion of the university in different areas of knowledge, covering the regional area of Braço do Norte, Criciúma, Laguna and Tubarão. The IFSC is an institutional partner in this initiative, which seeks regional development, interdisciplinarity and interaction between the university and society.

1 Técnica em Agroindústria (IFSC), graduada em Tecnologia de Alimentos (IFSC), pós-graduanda em Tecnologia de Bebidas Alcoólicas Pública (IFSC).

2 Enfermeira. Especialista em Ginecologia e Obstetrícia. Docente do Centro de Educação Profissional - CEDUP - Chapecó. 


\section{KEYWORDS}

Extensionist Core. Exchange. Interdisciplinarity. Interaction.

\section{Relato de experiência}

Através da extensão universitária é possível repassar à sociedade os conhecimentos educativos, culturais e científicos adquiridos na sala de aula, viabilizando uma interação transformadora entre a instituição e a comunidade. 0 Instituto Federal de Santa Catarina (IFSC), em parceria com a Universidade do Estado de Santa Catarina (Udesc), atuaram com a finalidade de selecionar bolsistas para participarem do Núcleo Extensionista Rondon.

0 Núcleo Extensionista Rondon (NER) da Udesc vem possibilitando 0 intercâmbio entre as instituições e universidades e tem 0 objetivo de promover a integração social e interdisciplinar das instituições de ensino superior, envolvendo estudantes de forma voluntária em busca de soluções que contribuam para 0 desenvolvimento sustentável de comunidades, ampliando 0 bem-estar da população.

Busca-se, assim, a garantia da interdisciplinaridade, da interação entre a universidade e a sociedade e da qualidade e do impacto das ações de Extensão no âmbito da Udesc, reforçando a missão da universidade diante da realidade social.

A diversidade das áreas de origem dos acadêmicos possibilitou o fortalecimento das noções de interdisciplinaridade para o desenvolvimento das oficinas realizadas no município, contando com as áreas de enfermagem, educação física, física, matemática, fisioterapia, medicina, história, tecnologia em alimentos, engenharia do petróleo, engenharia agronômica e sanitária.

A operação aqui relatada foi realizada no município de Garopaba, litoral Sul de Santa Catarina, onde os alunos tiveram a oportunidade de colocar em prática todos os conhecimentos adquiridos no decorrer de sua graduação, aliando teoria e prática.

Nesta edição do projeto, mais de 300 acadêmicos, dos quais 15 do IFSC, participaram de atividades em 22 municípios na área de abrangência das agências de Desenvolvimento Regional de Braço do Norte, Criciúma, Laguna e Tubarão, entre 12 e 22 de julho.

Figura 1: Gincana com alunos da escola municipal de Garopaba.

Fonte: Núcleo Extensionista Rondon

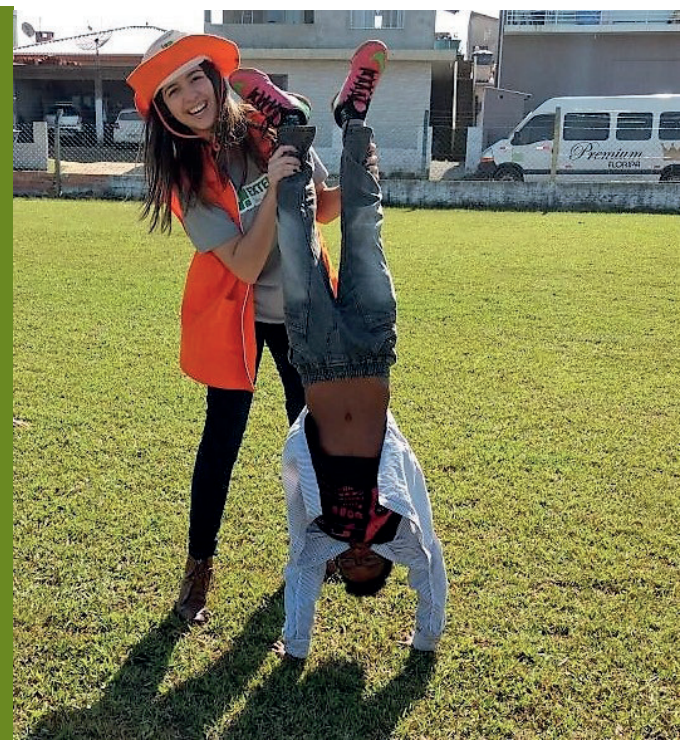

A primeira gincana foi realizada em uma escola municipal (Figura 1) em que os alunos do ensino fundamental puderam participar das brincadeiras com muita diversão. As gincanas eram constituídas por professores da própria escola, em parceria com os alunos extensionistas; nelas foram utilizadas bolas de futebol para brincar e fazer jogos com as crianças, além da corrida no saco entre três turmas, entre outras brincadeiras. A interação com as crianças foi de suma importância para conhecer o meio em que elas vivem e a sua realidade na escola. 
Realizamos atividades recreativas na praça principal de Garopaba, ocorrendo a interação entre a população com o Núcleo Extensionista Rondon. A oficina foi realizada em um domingo, visto que as famílias gostavam de passear na praça com as crianças. Foram levados papéis em branco, tintas guache e pincéis para alcançar a interação entre os extensionistas e a comunidade.

Além das atividades recreativas, houve o "abraço grátis" para quem quisesse participar, criando assim um laço afetivo com a comunidade. As pessoas que participavam, perguntavam sobre 0 Núcleo Extensionista, parabenizando os acadêmicos pela ação voluntária.

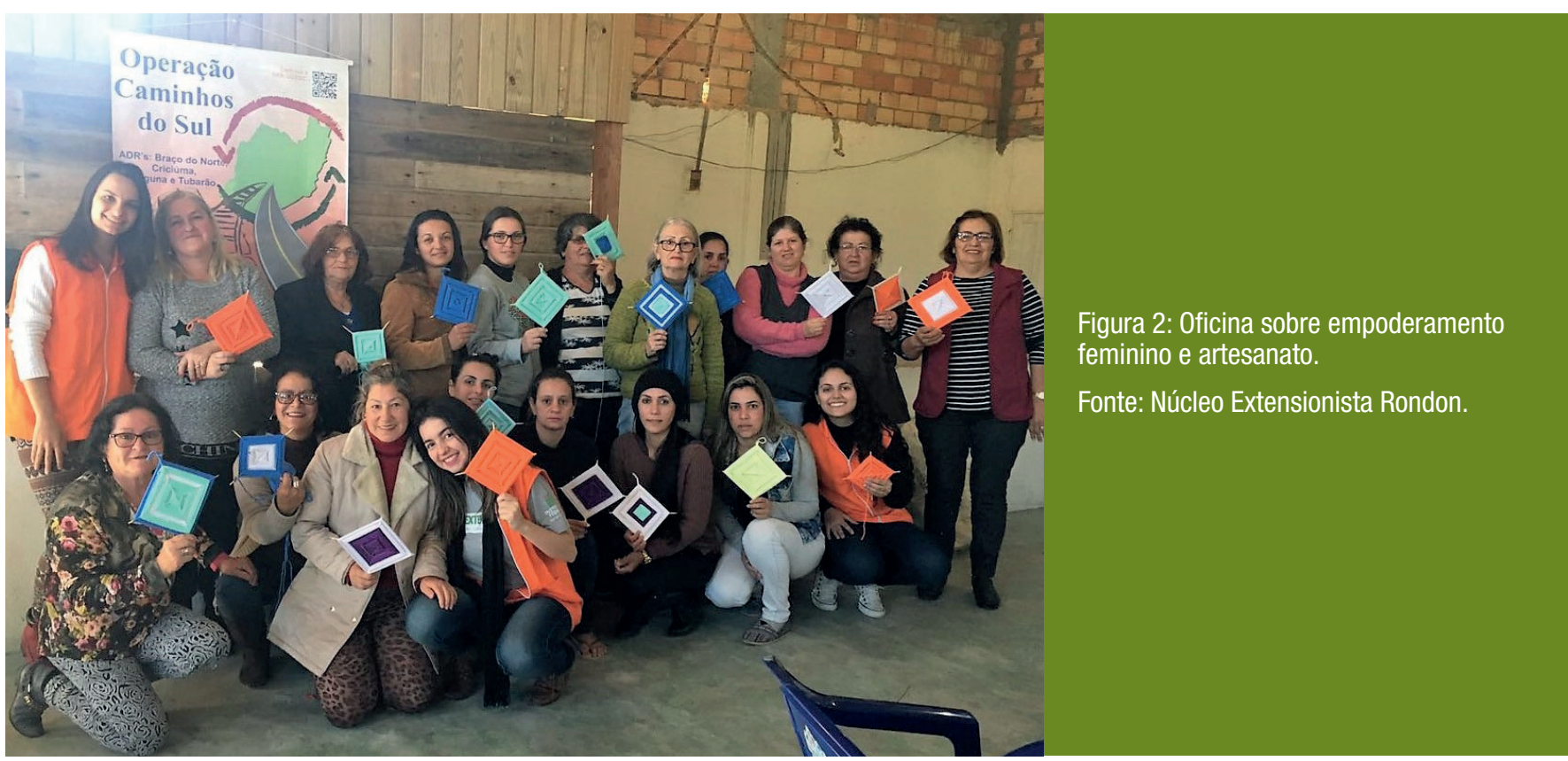

Como mostra a Figura 2, foi realizada uma oficina sobre empoderamento feminino com um grupo de mulheres pertencentes a uma comunidade deslocada de Garopaba. Foi realizado um debate sobre a cultura machista, violência contra a mulher e sobre os direitos das mulheres. Enquanto ocorria o debate, foram desenvolvidas mandalas como forma de aprendizagem sobre artesanato, causando uma participação mais ativa do público alvo. Observou-se que a maioria das mulheres sofriam com a desigualdade de gênero em relação a serviços domésticos, pois de acordo com os relatos elas eram responsáveis por todos os afazeres, enquanto seus maridos apenas praticavam seus hobbies, como ver jogo de futebol ou sair com os amigos.

No final da oficina, foi realizada uma dinâmica para questionar as mulheres presentes sobre 0 que elas pensavam de si próprias. Foi colocado um espelho dentro de uma bolsa fechada, e cada mulher que abria a bolsa via o espelho e apontava o que estava vendo, destacando a sua aparência, o seu estado emocional, como esta pessoa se sentia em casa, diante da família, do marido e como poderia melhorar diante da situação.

Empoderar mulheres e promover a equidade de gênero em todas as atividades sociais e da economia são garantias para 0 efetivo fortalecimento das economias, 0 impulsionamento dos negócios, a melhoria da qualidade de vida de mulheres, homens e crianças e para 0 desenvolvimento sustentável (ONU, 2018). 
Figura 3: Oficina realizada no Centro de Atenção Psicossocial - CAPS.

Fonte: Núcleo Extensionista Rondon.

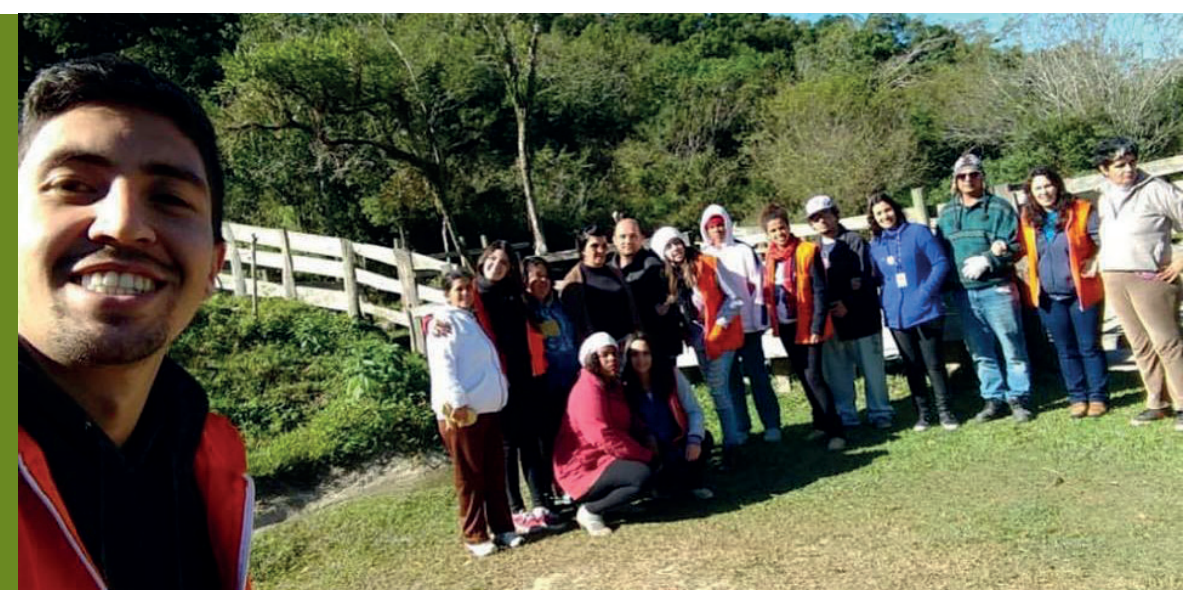

A atenção psicossocial prestada pelo Centro de Atenção Psicossocial (Caps) pressupõe um acolhimento dos sujeitos com sofrimento psíquico e transtorno mental, um conjunto de ações que visam à substituição da lógica manicomial como base de sustentação teórica para o cuidado em saúde mental e do modo asilar como paradigma das práticas dominantes (OLIVEIRA, 2009).

0 grupo ficou no período matutino e vespertino no Caps, acompanhando os pacientes, conhecendo as suas histórias de vida. Um passeio no quarteirão ajudou a promover a afinidade entre 0 grupo. Foram realizadas brincadeiras, danças e desenho. Houve muita interação entre os alunos e o grupo.

Atualmente a universidade tem se pautado no ensino, pesquisa e extensão, uma vez que desde o final do século XIX deixa de focar apenas o ensino como sua função por excelência e passa a desenvolver também a pesquisa.

A Operação Caminhos do Sul bateu o recorde de mais de 47 mil pessoas atendidas em atividades de extensão. No total, foram 1.250 oficinas realizadas e 340 extensionistas participantes. Houve ações gratuitas nas oito áreas da extensão universitária: educação; saúde; meio ambiente; direitos humanos e justiça; cultura; comunicação; trabalho; e tecnologia e produção.

A extensão pode ser notada como uma resposta da universidade para a sociedade que a financia; ação com foco em todas comunidades catarinense e/ou brasileira; ação da academia para as comunidades e a ação de compartilhamento entre 0 saber científico, produzido nesta academia, e o do senso comum presente na comunidade.

\section{Referências}

NÚCLEO EXTENSIONISTA RONDON. In: UDESC. Disponível em: http://www.udesc.br/ nucleorondon. Acesso em: 25 de fev. 2018.

OLIVEIRA, W. F. Éticas em conflito: reforma psiquiátrica e lógica manicomial. Caderno

Brasileiro de Saúde Mental, Florianópolis, v. 1, n. 2, p. 48-61, out./dez. 2009. Disponível em: http://periodicos.incubadora. ufsc.br/index.php/cbsm/article/view/1126. Acesso em: 27 fev. 2018.

ONU MULHERES BRASIL. In: ONU. Disponível em: http://www.onumulheres.org.br/referencias/ principios-de-empoderamento-das-mulheres/. Acesso em: 25 fev. 2018. 